\title{
Long-term outcomes of intravitreous bevacizumab or tissue plasminogen activator or vitrectomy for macular edema due to branch retinal vein occlusion
}

This article was published in the following Dove Medical Press journal:

Clinical Ophthalmology

\author{
Kazuyuki Kumagai' \\ Nobuchika Ogino² \\ Marie Fukami' \\ Mariko Furukawa' \\ 'Kami-iida Daiichi General Hospital, \\ Nagoya, Aichi, Japan; ${ }^{2}$ Shinjo \\ Ophthalmologic Institute, Miyazaki, \\ Japan
}

\begin{abstract}
Purpose: The purpose of this study was to determine the long-term outcomes of intravitreal bevacizumab (IVB) or intravitreal tissue plasminogen activator (tPA) or vitrectomy for macular edema associated with a branch retinal vein occlusion (BRVO).
\end{abstract}

Methods: This was a retrospective, interventional case series. Forty-one patients received a single $1.25 \mathrm{mg}$ of IVB injection and followed by pro re nata protocol, 71 patients received a single intravitreal tPA, and 116 patients underwent phacovitrectomy with intraocular lens implantation. Results: The baseline characteristics and follow-up periods were not significantly different among the three groups. The mean follow-up period was 55.5 months with a range of $12-160$ months. Sixteen patients $(39.0 \%)$ in the IVB group, 24 patients $(33.8 \%)$ in the tPA group, and two patients (1.7\%) in the vitrectomy group underwent additional surgeries during the follow-up period. The best-corrected visual acuity (BCVA) significantly improved in all groups at 1 year after the initial treatment (all, $P<0.0001)$ and at the final visit (all, $P<0.0001$ ). The differences in the BCVA between the three groups were not significant at all times after the initial treatment.

Conclusion: The three groups led to similar long-term good visual outcomes. However, additional surgeries were performed in more than $30 \%$ of patients in the IVB and PPA groups. Keywords: branch retinal vein occlusion, bevacizumab, tissue plasminogen activator, vitrectomy, macular edema

\section{Introduction}

Macular edema is a common cause of visual reduction in eyes with a branch retinal vein occlusion (BRVO). The main methods to treat BRVO include macular grid laser photocoagulation, intravitreal or posterior sub-tenon injection of triamcinolone acetonide, intravitreal injection of tissue plasminogen activator (tPA), and vitrectomy. ${ }^{1-3}$

Recently, intravitreal injections of anti-vascular endothelial growth factor (anti-VEGF) agents have become the standard treatment for this condition. However, there are several problems, for example, recurrence of macular edema which then requires repeat injections that can then increase the risk of complications. In addition, anti-VEGF agents are expensive, and repeated injections can become a financial burden on the patients. ${ }^{1,2,4-10}$

Several authors have reported on the effectiveness of intravitreal bevacizumab (IVB; Avastin), ${ }^{11-20}$ intravitreal tPA, ${ }^{21-25}$ and vitrectomy ${ }^{26-39}$ for the treatment of the macular edema associated with a BRVO. We have reported that these three different types of treatments had similar visual outcomes; however, one-third of eyes in the IVB and tPA groups required additional surgeries. ${ }^{36}$ A longer follow-up period 
was required to determine the final outcomes of these three treatments because vitrectomy was performed several years after the initial treatment in some eyes. We have extended the follow-up periods of the three groups especially for the IVB group. As a result, the mean follow-up period exceeded 50 months in all groups.

The purpose of this study was to determine the long-term outcomes of IVB or intravitreal tPA or vitrectomy on the macular edema associated with a BRVO.

\section{Methods}

\section{Patients}

We reviewed the medical records of the Kami-iida First General Hospital, the Shinjo Ophthalmologic Institute, and the Nishigaki Ophthalmologic Institute from January 2004 and March 2009. All patients who were diagnosed with a macular edema secondary to BRVO and had undergone either treatment, IVB (Avastin; Genentech Inc, San Francisco, CA), tPA (Monteplase, Eisai, Tokyo, Japan), or vitrectomy, were included.

The inclusion criteria were onset of $<6$ months, a progressive decrease in the visual acuity, and macular edema with symptoms and foveal hemorrhages. The exclusion criteria included eyes with vitreous hemorrhage, severe cataract, vitreomacular traction, presence of an epiretinal membrane, prior vitreoretinal surgery, prior macular grid laser photocoagulation, uncontrolled glaucoma, and other ocular diseases that could cause a reduction in vision.

All patients had signed an informed consent for the surgery, data collection, and the use of the data for research studies. The Ethics Committee of the hospitals approved the procedures used in this study, and the procedures conformed to the tenets of the Declaration of Helsinki.

All the patients had a complete ophthalmic examination including measurements of the best-corrected visual acuity (BCVA), slit-lamp biomicroscopy, indirect ophthalmoscopy, fundus photography, fluorescein angiography, and foveal thickness accessed by optical coherence tomography (OCT 3; Carl Zeiss Meditec AG, Jena, Germany).

Patients were examined preoperatively (baseline) and at 1 day, 1 week, 1, 2, 3, and 6 months after the treatment. The patients were examined every 3-6 months thereafter.

\section{Surgical procedures}

All surgeries were performed by one experienced surgeon (NO). Phacovitrectomy with intraocular lens implantation was performed on all phakic patients to avoid posttreatment cataract progression. Standard three-port pars plana vitrectomy was performed. A separation of the posterior hyaloid from the optic disk and posterior retina was performed when a posterior vitreous detachment was not present. All eyes had triamcinolone-assisted internal limiting membrane peeling. No eyes had intraocular or periocular triamcinolone injections.

\section{Intravitreal injections of bevacizumab and tPA}

The intravitreal injection was given through the pars plana with a 30-gauge needle under sterile conditions in the operating room. For the IVB group, each patient received a single intravitreal injection of $1.25 \mathrm{mg} / 0.05 \mathrm{~mL}$ bevacizumab and were followed with a pro re nata $(\mathrm{PRN})$ regimen. Additional injections were received when a persistent or recurrent macular edema was documented by OCT. A recurrent macular edema was defined as foveal thickness increased by $>30 \%$ after an initial decrease or a worsening of the BCVA by $>0.2$ logarithm of minimum angle resolution (logMAR) units after an initial improvement.

In the IVB group, all patients were classified into three types. In the "good response type," the macular edema was resolved within three IVB injections, and the foveal thickness was maintained during follow-up periods. The second type was named the "vitrectomized type" because a recurrence or persistence of the macular edema was treated with vitrectomy. In the "persistent type," the recurrence or persistence of macular edema remained during the entire follow-up period.

In the tPA group, each patient was given an intravitreal injection of 40,000 international units of tPA diluted with $0.25 \mathrm{~mL}$ of balanced salt solution and was instructed to maintain a supine position for 1-3 hours after the injection.

\section{Statistical analyses}

The decimal visual acuities were converted to the logMAR units for the statistical analyses. The paired $t$-tests were used to determine the significance of the differences in the BCVAs and foveal thicknesses, and chi-squared tests were used to determine the significance of the differences in the ratios of the BCVA and patients' characteristics. The differences in the measured values among the groups were compared by ANOVA with post hoc comparisons tested by the Scheffe procedure. An improvement or worsening of the visual acuity was defined as changes that were greater or lesser than $0.2 \log$ MAR units. A $P<0.05$ was accepted as statistically significant. Statistical analyses of data were carried out with the Statview 5.0 software (SAS Institute Inc., Cary, NC, USA). 


\section{Results}

Two hundred thirty-eight eyes of 238 patients met our inclusion criteria. Ten patients were excluded from the statistical analyses because they had been followed for $<12$ months. Therefore, the analyses were performed on 228 eyes of 228 patients. Three groups were identified; 41 eyes had received IVB, 71 eyes had received intravitreal tPA, and 116 eyes had undergone vitrectomy.

The follow-up period was extended in 130 (57.0\%) of the 228 patients. The mean extended follow-up period was 41 months with a range of 1-119 months. The mean follow-up period was $>50$ months for all groups. The follow-up period was at least 3 years in 155 eyes $(68.0 \%)$ and at least 5 years in 70 eyes $(30.7 \%)$.

The mean number of IVB during the follow-up period was 2.9 with a range of $1-7$. For all eyes, nine eyes $(22.0 \%)$ received one, eight eyes $(19.5 \%)$ received two, eight eyes (19.5\%) received three, 13 eyes $(31.7 \%)$ received four, two eyes $(4.9 \%)$ received five, and one eye $(2.4 \%)$ received seven IVB injections.
In the IVB group, 15 eyes were placed in the good response type, 12 eyes in the vitrectomized type, and 14 eyes in the persistent type. The mean numbers of injections were 1.7, 3.9, and 3.2 for good response, vitrectomy, and persisted type, respectively.

The demographics and baseline characteristics of the patients are shown in Table 1 . There were no significant differences among the groups except for the BCVA $\geqq 20 / 40$. The BCVA $\geqq 20 / 40$ was significantly higher in tPA group than in IVB and vitrectomy group; hence, there was no significance in the mean BCVA in logMAR. The patients with poorer visual acuity were found more frequently in the vitrectomy group.

A summary of the BCVAs and the foveal thicknesses at 12 months and at the final examination is presented in Table 2. There were no significant differences among the three groups except in the foveal thickness at 12 months and at the final visit. The mean thickness of the fovea was significantly thicker in the IVB and vitrectomy groups than in the tPA group at 12 months $(P=0.0022$ and $P=0.017$,

Table I Demographics and baseline characteristics

\begin{tabular}{|c|c|c|c|c|}
\hline & Bevacizumab & tPA & Vitrectomy & \multirow[t]{2}{*}{$P$-value } \\
\hline & $(n=4 I)$ & $(n=7 I)$ & $(n=116)$ & \\
\hline Age, years, mean $\pm S D$ & $66.0 \pm 12.2$ & $66.4 \pm 10.4$ & $66.0 \pm 10.5$ & 0.97 \\
\hline Female, n (\%) & $19(46.3)$ & $32(45.1)$ & $62(55.2)$ & 0.34 \\
\hline \multicolumn{5}{|l|}{ Lens status, n (\%) } \\
\hline Phakic & $39(95.1)$ & $63(88.7)$ & III (95.7) & \\
\hline Pseudophakic & $2(4.9)$ & $8(11.3)$ & $5(4.3)$ & 0.16 \\
\hline \multicolumn{5}{|l|}{ Duration of symptoms, months } \\
\hline Mean \pm SD & $2.6 \pm 1.4$ & $2.4 \pm I .1$ & $2.6 \pm 5.1$ & 0.44 \\
\hline \multicolumn{5}{|l|}{$B C V A$ in logMAR } \\
\hline Mean \pm SD & $0.52 \pm 0.34$ & $0.49 \pm 0.38$ & $0.61 \pm 0.37$ & 0.08 \\
\hline \multicolumn{5}{|l|}{ BCVA (Snellen equivalent) } \\
\hline$\leqq 20 / 200, \mathrm{n}(\%)$ & $9(22.0)$ & II (I5.5) & $28(24.1)$ & 0.37 \\
\hline$\geqq 20 / 40, \mathrm{n}(\%)$ & $16(39.0)$ & $32(45.1)$ & $32(27.6)$ & 0.04 \\
\hline First branch, n (\%) & $19(46.3)$ & $38(53.5)$ & $57(49.1)$ & \\
\hline Second branch, n (\%) & $22(53.6)$ & $33(46.5)$ & $59(50.9)$ & 0.74 \\
\hline No PVD, n (\%) & $24(58.5)$ & $51(71.8)$ & $67(57.8)$ & 0.13 \\
\hline Scatter photocoagulation, n (\%) & $6(14.6)$ & $4(5.6)$ & $13(11.2)$ & 0.27 \\
\hline \multicolumn{5}{|l|}{ Foveal thickness } \\
\hline Mean \pm SD & $554 \pm 201$ & $538 \pm 176$ & $556 \pm 206$ & 0.83 \\
\hline IOL at last visit, n (\%) & $16(39.0)$ & $31(43.7)$ & $116(100)$ & \\
\hline \multicolumn{5}{|l|}{ Follow-up duration, months } \\
\hline Mean \pm SD & $57.0 \pm 35.7$ & $53.8 \pm 36.9$ & $56.0 \pm 36.9$ & 0.89 \\
\hline Range & $12-119$ & $12-143$ & $12-160$ & \\
\hline
\end{tabular}

Abbreviations: logMAR, logarithm of minimum angle resolution; PVD, posterior vitreous detachment; BCVA, best corrected visual acuity; IOL, intraocular lens; tPA, tissue plasminogen activator. 
Table 2 Summary of the BCVA and the foveal thickness

\begin{tabular}{|c|c|c|c|c|}
\hline & Bevacizumab & tPA & Vitrectomy & \multirow[t]{2}{*}{$P$-value } \\
\hline & $(n=4 I)$ & $(n=7 I)$ & $(n=116)$ & \\
\hline \multicolumn{5}{|l|}{ At 12 months } \\
\hline \multicolumn{5}{|l|}{ BCVA (logMAR) } \\
\hline Mean \pm SD & $0.20 \pm 0.34$ & $0.18 \pm 0.31$ & $0.2 I \pm 0.34$ & 0.80 \\
\hline \multicolumn{5}{|l|}{ BCVA (Snellen equivalent) } \\
\hline$V A \geqq 20 / 40, n(\%)$ & $29(70.7)$ & $53(74.6)$ & $89(76.7)$ & 0.75 \\
\hline$V A \geqq 20 / 20, n(\%)$ & $13(3 \mid .7)$ & $29(40.8)$ & $4 \mathrm{I}(35.3)$ & 0.59 \\
\hline Degree of visual improvement, mean \pm SD & $0.31 \pm 0.33$ & $0.30 \pm 0.36$ & $0.39 \pm 0.33$ & 0.18 \\
\hline Improved, n (\%) & $29(70.7)$ & $46(64.8)$ & $81(69.8)$ & \\
\hline Unchanged, n (\%) & $10(24.4)$ & $21(29.6)$ & $29(25.0)$ & \\
\hline Worsened, n (\%) & $2(4.9)$ & $4(5.6)$ & $6(5.2)$ & 0.93 \\
\hline \multicolumn{5}{|l|}{ Foveal thickness $(\mu \mathrm{m})$} \\
\hline Mean \pm SD & $350 \pm 218$ & $227 \pm 127$ & $304 \pm 169$ & 0.001 \\
\hline \multicolumn{5}{|l|}{ At the final visit } \\
\hline \multicolumn{5}{|l|}{ BCVA (logMAR) } \\
\hline Mean \pm SD & $0.19 \pm 0.32$ & $0.15 \pm 0.32$ & $0.16 \pm 0.36$ & 0.83 \\
\hline \multicolumn{5}{|l|}{ BCVA (Snellen equivalent) } \\
\hline $\mathrm{VA} \geqq 20 / 40, \mathrm{n}(\%)$ & $32(78.0)$ & $56(78.9)$ & $96(82.8)$ & 0.75 \\
\hline$V A \geqq 20 / 20, n(\%)$ & $17(4 \mid .5)$ & $34(47.9)$ & $55(47.4)$ & 0.59 \\
\hline Degree of visual improvement, mean \pm SD & $0.33 \pm 0.32$ & $0.34 \pm 0.36$ & $0.44 \pm 0.34$ & $0.06 \mathrm{I}$ \\
\hline Improved, n (\%) & $27(65.9)$ & $48(67.6)$ & $87(75.0)$ & \\
\hline Unchanged, n (\%) & $13(31.7)$ & $20(28.2)$ & $27(23.3)$ & \\
\hline Worsened, n (\%) & $\mathrm{I}(2.4)$ & $3(4.2)$ & $2(1.7)$ & 0.93 \\
\hline \multicolumn{5}{|l|}{ Foveal thickness $(\mu \mathrm{m})$} \\
\hline Mean \pm SD & $298 \pm 189$ & $214 \pm 101$ & $25 I \pm 120$ & 0.0045 \\
\hline
\end{tabular}

Abbreviations: BCVA, best corrected visual acuity; logMAR, logarithm of minimum angle resolution; tPA, tissue plasminogen activator.

respectively). The mean foveal thickness in the tPA group was significantly thinner than that in the IVB group at the final visit $(P=0.0047)$. There were no retinal tears, detachments, or infections resulting from the intravitreal injections.

The postoperative adverse events and the need for additional surgeries are shown in Tables 3 and 4. Sixteen patients $(39.0 \%)$ in the IVB group, 24 patients $(33.8 \%)$ in the tPA group, and two patients (1.7\%) in the vitrectomy group underwent additional surgeries during the follow-up period. During the extended follow-up periods, two patients in the IVB group underwent vitrectomy for persistent macular edema, and one patient underwent vitrectomy for vitreous hemorrhage. In the tPA group, two patients underwent vitrectomy for an epiretinal membrane, and one patient underwent vitrectomy for vitreous hemorrhage. Cataract surgery was performed when lens opacity progressed even slightly, and the rate of cataract surgery for phakic eyes at the final visit was $15 / 39(38.5 \%)$ in the IVB group and $24 / 63$ (38.1\%) in
Table 3 Postoperative adverse events

\begin{tabular}{|l|l|l|l|}
\hline & Bevacizumab & tPA & Vitrectomy \\
\cline { 2 - 4 } & $(\mathbf{n}=\mathbf{4 I})$ & $\mathbf{( n = 7 I )}$ & $\mathbf{( n = I ~ I 6 )}$ \\
\hline Epiretinal membrane & 3 & 8 & 0 \\
\hline Vitreous hemorrhage & 2 & 3 & 0 \\
\hline Glaucoma & $\mathrm{I}$ & $\mathrm{I}$ & 3 \\
\hline RRD & 0 & 0 & $\mathrm{I}$ \\
\hline Foveal hard exudate & $\mathrm{I}$ & 0 & $\mathrm{I}$ \\
\hline Subretinal fibrosis & 0 & $\mathrm{I}$ & $\mathrm{I}$ \\
\hline $\begin{array}{l}\text { Choroidal } \\
\text { neovascularization }\end{array}$ & 0 & 0 & $\mathrm{I}$ \\
\hline $\begin{array}{l}\text { Descemet membrane } \\
\text { folding }\end{array}$ & 0 & $\mathrm{I}$ & 0 \\
\hline Fibrin membrane & 0 & $\mathrm{I}$ & 0 \\
\hline Subretinal hemorrhage & 0 & $\mathrm{I}$ & 0 \\
\hline Subcapsular cataract & 0 & $\mathrm{I}$ & 0 \\
\hline Cerebral infarction & 0 & $\mathrm{I}$ & 3 \\
\hline
\end{tabular}

Note: Data are expressed as number.

Abbreviations: RRD, rhegmatogenous retinal detachment; tPA, tissue plasminogen activator. 
Table 4 Additional surgeries

\begin{tabular}{|c|c|c|c|}
\hline & Bevacizumab & tPA & Vitrectomy \\
\hline & $(n=4 I)$ & $(n=7 I)$ & $(n=116)$ \\
\hline IOL & 5 & 18 & 0 \\
\hline PPV & 3 & 2 & 2 \\
\hline IOL+PPV & 10 & 6 & 0 \\
\hline Glaucoma surgery & 1 & 0 & 0 \\
\hline \multicolumn{4}{|l|}{ Indication for vitrectomy } \\
\hline $\begin{array}{l}\text { Persistent macular } \\
\text { edema }\end{array}$ & 11 & 2 & 0 \\
\hline Vitreous hemorrhage & 2 & 3 & 0 \\
\hline Epiretinal membrane & 0 & 3 & 0 \\
\hline Subretinal hard exudate & 0 & 0 & 1 \\
\hline RRD & 0 & 0 & 1 \\
\hline
\end{tabular}

Note: Data are expressed as number.

Abbreviations: IOL, intraocular lens; PPV, pars plana vitrectomy; RRD, rhegmatogenous retinal detachment; tPA, tissue plasminogen activator.

the tPA group. At 2 weeks after the cataract surgery none of these eyes had an improvement of the BCVA.

The time course for the difference in the BCVA and the degree of visual improvement for all groups is shown in Figures 1 and 2, respectively. The BCVA improved in all groups, and the changes in the BCVA from the baseline were significant at all time points $(P<0.0001$ to 0.0017$)$. A continuation of the visual improvement was observed in the tPA and vitrectomy groups. Early visual improvement was observed in the IVB group. The difference in the BCVA between 12 months and the final was statistically significant only in the vitrectomy group ( $P=0.0075)$. Moreover, the degree of visual improvement between 12 months and the final was significant in the vitrectomy group $(P=0.0075)$. Although the response to the IVB was rapid, the changes in

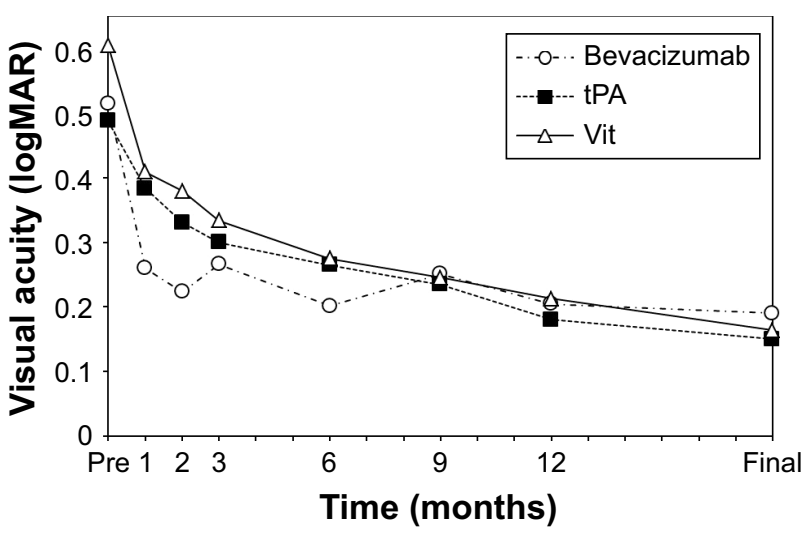

Figure I Time course of the changes in the BCVA for all groups. Continued visual improvement was observed in the tPA and vitrectomy groups. Rapid visual improvement was observed in the bevacizumab group.

Abbreviations: BCVA, best-corrected visual acuity; tPA, tissue plasminogen activator; logMAR, logarithm of minimum angle resolution; Vit, vitrectomy.

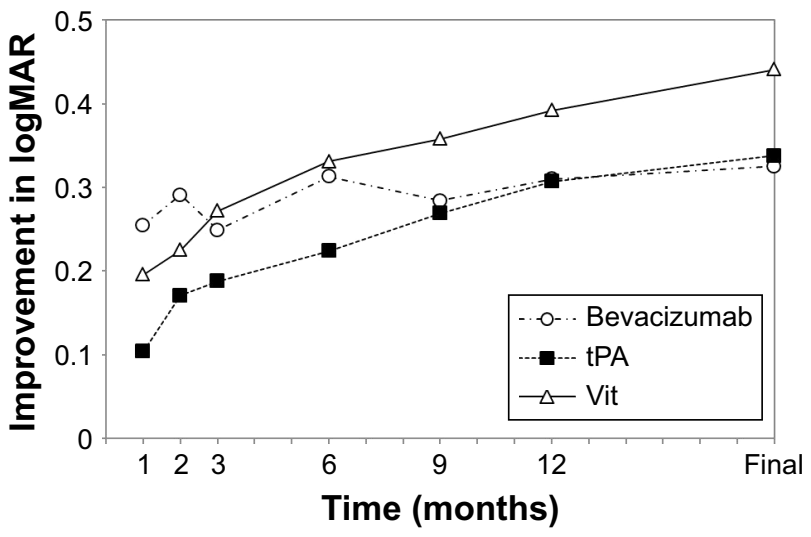

Figure 2 Time course of the changes in the degree of visual improvement in logMAR for all groups.

Abbreviations: tPA, tissue plasminogen activator; logMAR, logarithm of minimum angle resolution; Vit, vitrectomy.

the BCVA between the three groups were not significant at all time points.

Figure 3 shows the time course of the difference in the foveal thickness for all groups. In all groups, the foveal thickness decreased postoperatively, and the changes in the foveal thickness from the baseline was significant at all time points (all, $P<0.0001$ ). A continuation of the decrease of the foveal thickness was observed in the tPA and vitrectomy groups during the extended follow-up period. An early decrease in the foveal thickness was observed in IVB group. The difference in the foveal thickness between 12 months and the final visit was statistically significant only in the vitrectomy group $(P<0.0001)$. The mean foveal thickness in the IVB group was significantly thinner than that in the tPA and vitrectomy groups during the early postoperative period at 1 month $(P=0.015$ and $P=0.0018$, respectively) and at 2 months ( $P=0.039$ and $P=0.007$, respectively).

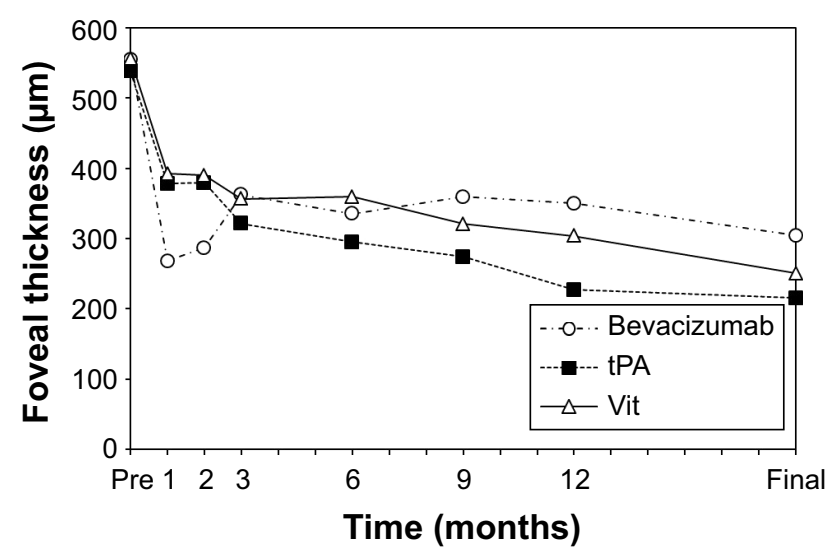

Figure 3 Time course of the changes in the foveal thickness for all groups. A continued decrease in the foveal thickness was observed in the tPA and vitrectomy groups. A rapid decrease in the foveal thickness is present in the bevacizumab group. Abbreviations: tPA, tissue plasminogen activator; Vit, vitrectomy. 
Table 5 presents the characteristics of the patients who underwent vitrectomy for persistent macular edema. Eleven patients were in the IVB group and two patients were in the IPA group. Of the 11 patients in the IVB group, nine patients refused to have additional IVB injections and two patients did not have any visual and anatomical improvement after the injection. The mean interval from the initial treatment to the vitrectomy was 15.8 months with a range of $13-30$ months. The mean BCVA at the baseline was $0.50 \pm 0.36 \log$ MAR units, at previtrectomy was $0.45 \pm 0.37 \log$ MAR units, and at the final visit was $0.17 \pm 0.18 \log$ MAR units. The differences in the BCVAs between the final BCVA and baseline or pre-vitrectomy were significant ( $P=0.0099, P=0.0062$, respectively).

The mean foveal thickness at the baseline was $541 \pm 103 \mu \mathrm{m}$, at pre-vitrectomy was $536 \pm 172 \mu \mathrm{m}$, and at the final visit was $277 \pm 82 \mu \mathrm{m}$. The differences between the thicknesses at the final visit and the baseline or pre-vitrectomy were significant ( $P=0.0001, P=0.0002$, respectively).

The demographics and characteristics of the patients who underwent vitrectomy for postoperative complications are shown in Table 6. The mean interval from the initial treatment to the vitrectomy for a vitreous hemorrhage was 45.4 months with a range of 19-80 months. The mean interval from the initial treatment to vitrectomy for an epiretinal membrane was 61.0 months with a range of $20-133$ months. The vitrectomy was successful in all of the eyes.

Figures 4 and 5 demonstrate the time course of the difference in the BCVA and the foveal thickness for the three types of the IVB group. There were no significant differences among the types in the baseline BCVA and foveal thickness. There were no significant differences in the BCVA and the foveal thickness at all time points between the good response type and the vitrectomized type.

\section{Discussion}

The results showed that the BCVA was significantly improved at the end of the first year after the initial treatment in the three groups, and the BCVA was maintained for about 40 months thereafter. The differences in the BCVA between the three groups were not significant at all time points. However, $39.0 \%$ of patients in the IVB group, $33.8 \%$ in the tPA group, and $1.7 \%$ of patients in the vitrectomy group had to undergo additional surgeries during the follow-up period. Our findings indicate that the vitrectomy group had less chance of needing additional surgery but had comparable long-term visual results as the other two groups.

The time course of the changes in the BCVA and foveal thickness showed continued improvements in the tPA and

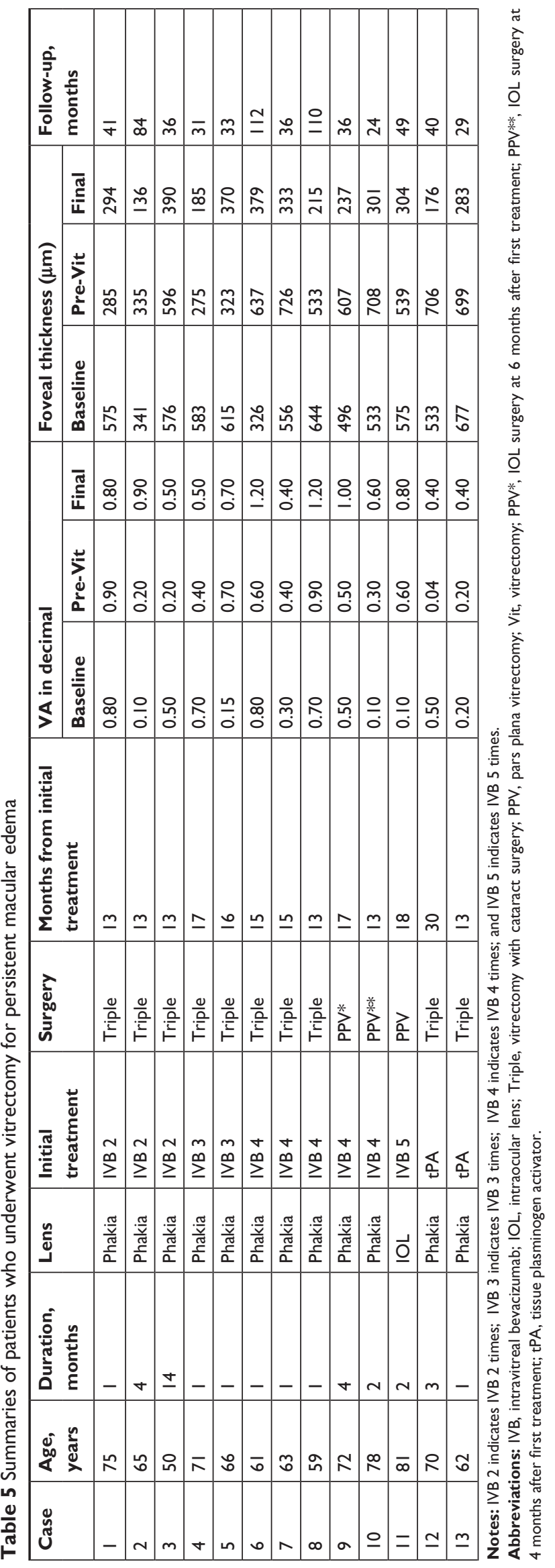


Table 6 Summaries of patients who underwent vitrectomy for complications

\begin{tabular}{|c|c|c|c|c|c|c|c|c|c|c|}
\hline \multirow[t]{2}{*}{ Case } & \multirow{2}{*}{$\begin{array}{l}\text { Age, } \\
\text { year }\end{array}$} & \multirow{2}{*}{$\begin{array}{l}\text { Initial } \\
\text { treatment }\end{array}$} & \multirow[t]{2}{*}{ Lens } & \multirow[t]{2}{*}{ Complication } & \multirow[t]{2}{*}{ Surgery } & \multirow{2}{*}{$\begin{array}{l}\text { Months from } \\
\text { initial treatment }\end{array}$} & \multicolumn{3}{|c|}{ VA in decimal } & \multirow{2}{*}{$\begin{array}{l}\text { Follow-up, } \\
\text { months }\end{array}$} \\
\hline & & & & & & & Baseline & Pre-Vit & Final & \\
\hline I & 52 & IVB I time & Phakic & $\mathrm{VH}$ & Triple & 30 & 0.50 & 1.50 & 1.50 & 92 \\
\hline 2 & 59 & IVB 3 times & Phakic & $\mathrm{VH}$ & Triple & 53 & 0.30 & 0.80 & 0.60 & 54 \\
\hline 3 & 72 & tPA & Phakic & $\mathrm{VH}$ & Triple & 80 & 0.70 & 0.30 & 1.00 & 90 \\
\hline 4 & 49 & tPA & Phakic & $\mathrm{VH}$ & Triple & 45 & 0.20 & 0.30 & 0.50 & 132 \\
\hline 5 & 82 & tPA & Phakic & $\mathrm{VH}$ & Triple & 19 & 0.30 & 0.80 & 1.00 & 44 \\
\hline 6 & 61 & tPA & Phakic & ERM & $\mathrm{PPV}^{*}$ & 20 & 0.40 & 0.70 & 0.90 & 30 \\
\hline 7 & 76 & tPA & Phakic & ERM & PPV** & 30 & 0.03 & 0.30 & 0.40 & 47 \\
\hline 8 & 65 & tPA & Phakic & ERM & Triple & 133 & 0.70 & 0.60 & 0.70 & 143 \\
\hline 9 & 59 & Vit & Phakic & RRD & PPV & 2 & 0.10 & 0.15 & 0.20 & 68 \\
\hline 10 & 55 & Vit & Phakic & Subretinal HE & PPV & 17 & 0.50 & 0.30 & 1.20 & 97 \\
\hline
\end{tabular}

Abbreviations: VH, vitreous hemorrhage; IVB, intravitreal bevacizumab; ERM, epiretinal membrane; RRD, rhegmatogenous retinal detachment; $\mathrm{HE}$, hard exudate; Triple, vitrectomy with cataract surgery; PPV, pars plana vitrectomy; Vit, vitrectomy; PPV*, cataract surgery at 16 months after first treatment; PPV**, cataract surgery at 13 months after first treatment; VA, visual acuity; tPA, tissue plasminogen activator.

vitrectomy groups and rapid and sustained improvements in the IVB group. The mean foveal thickness was significantly thinner in the IVB group than in the tPA and vitrectomy groups during the early postoperative period. The mean BCVA in the good response type of the IVB group was significantly better than that in the vitrectomy group at 2 months $(P=0.040)$. A retrospective analysis in the BRAVO and CRUISE trials showed that more than $50 \%$ of the patients treated with monthly intravitreal ranibizumab (IVR) injections achieved clinically significant improvements in their vision during the initial 6 months after the IVR ${ }^{40}$ The rapid and sustained improvements are advantages for the IVB injections and are also present with the other anti-VEGF agents. These findings indicate that IVB injections lead to rapid anatomical and functional improvements compared with the other groups.

Another advantage of IVB is its lower cost. The 2015 Medicare reimbursement for anti-VEGF therapy for macular

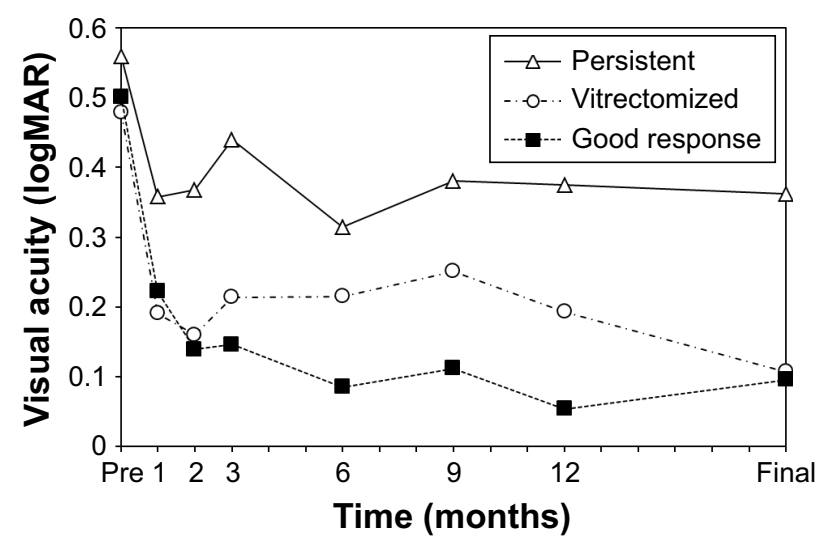

Figure 4 Time course of the changes in the BCVA for the three types of bevacizumab group.

Abbreviation: BCVA, best-corrected visual acuity. edema due to BRVO is $\sim \$ 1,967$ for ranibizumab, $\$ 1,961$ for aflibercept, and $\$ 17$ for bevacizumab. ${ }^{1}$ In addition, off-label repackaged bevacizumab and other anti-VEGF drugs such as aflibercept and ranibizumab are reported to be similarly effective in the treatment of patients with $\mathrm{RVO}^{1,7,8,41-43}$ and diabetic macular edema. ${ }^{7,44}$

Additional surgeries in the IVB and tPA groups included cataract surgery and vitrectomy for persistent macular edema, epiretinal membrane, and vitreous hemorrhage. The remaining phakic patients have the possibility of cataract surgery in the future. Not only the treatment but also aging is one of the causes for the cataract. Vitrectomy for epiretinal membrane was performed in three eyes of the tPA group at 20, 30, and 133 months after the initial treatment. Vitrectomy for vitreous hemorrhage was performed in two eyes in the IVB group at 30 and 53 months and in three eyes in the tPA group at 19, 45, and 80 months after the initial tPA injection.

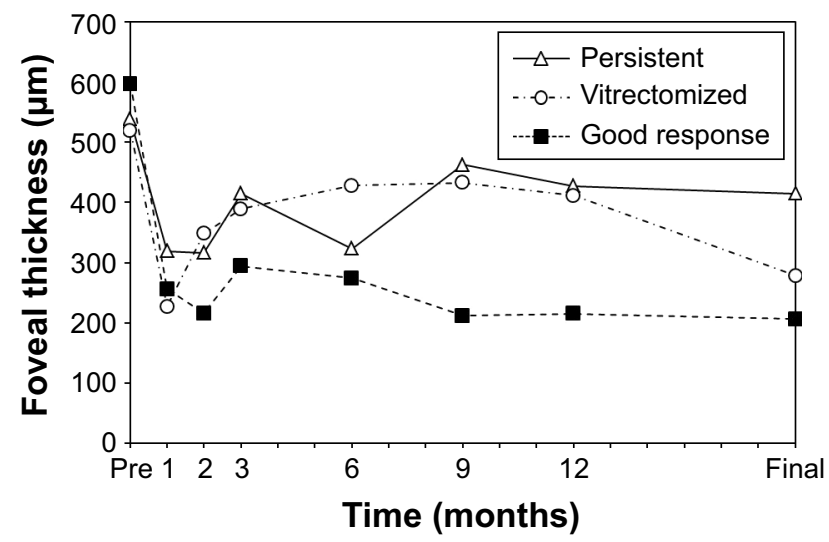

Figure 5 Time course of the changes in the foveal thickness for the three types of bevacizumab group.

Abbreviation: logMAR, logarithm of minimum angle resolution. 
Epiretinal membranes and vitreous hemorrhages are possibly associated with the abnormal vitreoretinal interface after IVB or intravitreal tPA injections. These findings indicated that further surgeries will possibly be needed after a long time after the IVB or intravitreal tPA injection perhaps even after other intravitreal injections.

Eleven eyes underwent vitrectomy for a recurrence or persistent macular edema in the IVB group, and they all had similar final BCVA with good responses. It is possible that other treatments such as an initial three IVB, another antiVEGF agent, or a combination of other treatments might obtain more favorable outcomes. However, our findings indicated that vitrectomy is a good optional treatment for persistent macular edema. Some authors have also reported that vitrectomy was effective for recurrent or persistent macular edema. . $^{34,38,39}$

The results showed that the vitrectomy group achieved visual outcomes comparable to IVB and tPA groups with fewer additional surgeries. Vitrectomy was reported to be a useful method in terms of the relative costs and benefits for diabetic macular edema ${ }^{4}$ and proliferative diabetic retinopathy. ${ }^{10}$ In addition, vitrectomy is an invasive procedure but has become a safer treatment option with the development of new technology, such as small-gauge instruments, wide-angle viewing systems, and safer dyes used for making the vitreous and membranes more visible. We believe that vitrectomy might be one of effective treatments for macular edema due to BRVO.

There are limitations in this study. First, this study was not a randomized study with a control group. Second, the effects of other anti-VEGF agents were not determined. Third, IVB might be under-treated. Fourth, the baseline VA was not equally distributed. The positive aspects of this study include a relatively large sample size, longer follow-up period, and the use of BCVA. In addition, all eyes except the clear phakic eyes were pseudophakic at the last visit so a worsening of nuclear sclerotic cataracts did not influence the final BCVA.

In conclusion, the BCVA and foveal thickness improve and are maintained for a long postoperative period after a single IVB injection and followed by PRN protocol, a single intravitreal tPA, and vitrectomy for macular edema due to BRVO. Although the final BCVA is comparable among three treatments, about one-third of the patients need additional surgeries after IVB or intravitreal tPA. Without the balanced baseline characteristics, one cannot conclude that vitrectomy was a more cost-effective way in treating patients with BRVO. However, vitrectomy might be considered as one of treatment options to treat persistent or treatment-naïve patients that could decrease the burden for patients and physicians.

\section{Disclosure}

The authors report no conflicts of interest in this work.

\section{References}

1. Ehlers JP, Kim SJ, Yeh S, et al. Therapies for macular edema associated with branch retinal vein occlusion: a report by the American Academy of Ophthalmology. Ophthalmology. 2017;124(9):1412-1423. doi:10.1016/j.ophtha.2017.03.060

2. Li J, Paulus YM, Shuai Y, Fang W, Liu Q, Yuan S. New developments in the classification, pathogenesis, risk factors, natural history, and treatment of branch retinal vein occlusion. J Ophthalmol. 2017;2017: 4936924.

3. Esmaili DD, Boyer DS. Recent advances in understanding and managing retinal vein occlusions. F1000Res. 2018;16(7):467. doi:10.12688/ f1000research.12886.1

4. Smiddy WE. Economic considerations of macular edema therapies. Ophthalmology. 2011;118:1827-1833. doi:10.1016/j.ophtha.2010. 12.034

5. Erie JC, Barkmeier AJ, Hodge DO, Mahr MA. High variation of intravitreal injection rates and medicare anti-vascular endothelial growth factor payments per injection in the United States. Ophthalmology. 2016;123:1257-1262. doi:10.1016/j.ophtha.2016.02.015

6. Ross EL, Hutton DW, Stein JD, Bressler NM, Jampol LM, Glassman AR. Diabetic retinopathy clinical research network. costeffectiveness of aflibercept, bevacizumab, and ranibizumab for diabetic macular edema treatment: analysis from the diabetic retinopathy clinical research network comparative effectiveness trial. JAMA Ophthalmol. 2016;134(8):888-896. doi:10.1001/jamaophthalmol.2016.1669

7. Low A, Kansagara D, Freeman M, et al. Comparative clinical and economic effectiveness of anti-vascular endothelial growth factor agents [Internet]. VA Evidence-based Synthesis Program Reports. Washington (DC): Department of Veterans Affairs (US); 2017 Jan.

8. Scott IU, VanVeldhuisen PC, Ip MS, et al. SCORE2 investigator group. Effect of bevacizumab vs aflibercept on visual acuity among patients with macular edema due to central retinal vein occlusion: the SCORE2 randomized clinical trial. JAMA. 2017;317(20):2072-2087. doi:10. 1001/jama.2017.4568

9. Wu AM, Wu CM, Greenberg PB, Yu F, Lum F, Coleman AL. The use of bevacizumab and ranibizumab for branch retinal vein occlusion in medicare beneficiaries. Am J Ophthalmol Case Rep. 2018;11:105-108. doi:10.1016/j.ajoc.2018.06.005

10. Lin J, Chang JS, Yannuzzi NA, Smiddy WE. Cost evaluation of early vitrectomy versus panretinal photocoagulation and intravitreal ranibizumab for proliferative diabetic retinopathy. Ophthalmology. 2018; pii: S0161-6420(18):30040-X.

11. Prager F, Michels S, Kriechbaum K, et al. Intravitreal bevacizumab (Avastin) for macular oedema secondary to retinal vein occlusion: 12-month results of a prospective clinical trial. Br J Ophthalmol. 2009; 93(4):452-456. doi:10.1136/bjo.2008.141085

12. Russo V, Barone A, Conte E, Prascina F, Stella A, Noci ND. Bevacizumab compared with macular laser grid photocoagulation for cystoid macular edema in branch retinal vein occlusion. Retina. 2009;29(4): 511-515. doi:10.1097/IAE.0b013e318195ca65

13. Gregori NZ, Rattan GH, Rosenfeld PJ, et al. Safety and efficacy of intravitreal bevacizumab (avastin) for the management of branch and hemiretinal vein occlusion. Retina. 2009;29(7):913-925. doi:10.1097/ IAE.0b013e3181aa8dfe

14. Kondo M, Kondo N, Ito Y, et al. Intravitreal injection of bevacizumab for macular edema secondary to branch retinal vein occlusion: results after 12 months and multiple regression analysis. Retina. 2009;29(9): 1242-1248. doi:10.1097/IAE.0b013e3181aa8e20 
15. Wu L, Arevalo JF, Berrocal MH, et al. Comparison of two doses of intravitreal bevacizumab as primary treatment for macular edema secondary to branch retinal vein occlusions: results of the Pan American collaborative retina study group at 24 months. Retina. 2009;29(10):1396-1403. doi:10.1097/IAE.0b013e3181bcef53

16. Hoeh AE, Ach T, Schaal KB, Scheuerle AF, Dithmar S. Long-term follow-up of OCT-guided bevacizumab treatment of macular edema due to retinal vein occlusion. Graefes Arch Clin Exp Ophthalmol. 2009; 247(12):1635-1641. doi:10.1007/s00417-009-1151-1

17. Jaissle GB, Leitritz M, Gelisken F, Ziemssen F, Bartz-Schmidt KU, Szurman P. One-year results after intravitreal bevacizumab therapy for macular edema secondary to branch retinal vein occlusion. Graefes Arch Clin Exp Ophthalmol. 2009;247(1):27-33. doi:10.1007/ s00417-008-0916-2

18. Kriechbaum K, Prager F, Geitzenauer W, et al. Association of retinal sensitivity and morphology during antiangiogenic treatment of retinal vein occlusion over one year. Ophthalmology. 2009;116(12):2415-2421. doi:10.1016/j.ophtha.2009.05.001

19. Ach T, Hoeh AE, Schaal KB, Scheuerle AF, Dithmar S. Predictive factors for changes in macular edema in intravitreal bevacizumab therapy of retinal vein occlusion. Graefes Arch Clin Exp Ophthalmol. 2010; 248(2):155-159. doi:10.1007/s00417-009-1167-6

20. Ivanovska Adjievska B, Boskurt S, Orovcanec N, Dimovska-Jordanova V. The outcome of low-frequency intravitreal bevacizumab therapy for macular edema in retinal vein occlusions. Clin Ophthalmol. 2017;11: 1183-1190. doi:10.2147/OPTH.S137380

21. Hattenbach L, Steinkamp G, Scharrer OC. Fibrinolytic therapy with low-dose recombinant tissue plasminogen activator in retinal vein occlusion. Ophthalmologica. 1998;212(6):394-398. doi:10.1159/000027374

22. Murakami T, Takagi H, Kita M, et al. Intravitreal tissue plasminogen activator to treat macular edema associated with branch retinal vein occlusion. Am J Ophthalmol. 2006;142(2):318-320. doi:10.1016/j.ajo.2006.02.039

23. Sakuma T, Mizota A, Inoue J, Tanaka M. Intravitreal injection of autologous plasmin enzyme for macular edema associated with branch retinal vein occlusion. Am J Ophthalmol. 2010;150(6):876-882. doi:10.1016/j. ajo.2010.06.005

24. Tagami M, Kusuhara S, Imai H, Honda S, Tsukahara Y, Negi A. Impact of intravitreal injection of tissue plasminogen activator on full-field electroretinogram in patients with macular oedema secondary to retinal vein occlusion. Ophthalmologica. 2011;226(2):81-86. doi:10.1159/000326242

25. Udaondo P, Díaz-Llopis M, García-Delpech S, Salom D, Romero FJ. Intravitreal plasmin without vitrectomy for macular edema secondary to branch retinal vein occlusion. Arch Ophthalmol. 2011;129(3):283-287. doi:10.1001/archophthalmol.2011.8

26. Tachi N, Hasimoto Y, Ogino N. Vitrectomy for macular edema combined with retinal vein occlusion. Doc Ophthalmol. 1999;97(3-4):465-469.

27. Shah GK, Sharma S, Fineman MS, et al. Arteriovenous adventitial sheathotomy for the treatment of macular edema associated with branch retinal vein occlusion. Am J Ophthalmol. 2000;129(1):104-106.

28. Mester U, Dillinger P. Vitrectomy with arteriovenous decompression and internal limiting membrane dissection in branch retinal vein occlusion. Retina. 2002;22(6):740-746.

29. Charbonnel J, Glacet-Bernard A, Korobelnik JF, et al. Management of branch retinal vein occlusion with vitrectomy and arteriovenous adventitial sheathotomy, the possible role of surgical posterior vitreous detachment. Graefe's Arch Clin Exp Ophthalmol. 2004;242(3):223-228. doi:10.1007/s00417-003-0824-4

30. Mandelcorn MS, Nrusimhadevara RK. Internal limiting membrane peeling for decompression of macular edema in retinal vein occlusion: a report of 14 cases. Retina. 2004;24(3):348-355.
31. Mason J 3 rd, Feist R, White M Jr, Swanner J, McGwin G Jr, Emond T. Sheathotomy to decompress branch retinal vein occlusion a matched control study. Ophthalmology. 2004;111(3):540-545. doi:10.1016/j. ophtha.2003.05.032

32. Kumagai K, Furukawa M, Ogino N, Larson E, Uemura A. Long-term visual outcomes after vitrectomy for macular edema with foveal hemorrhage in branch retinal vein occlusion. Retina. 2007;27(5):584-588. doi:10.1097/01.iae.0000249576.98520.25

33. Kumagai K, Furukawa M, Ogino N, Larson E, Uemura A. Long-term outcomes of vitrectomy with or without arteriovenous sheathotomy in branch retinal vein occlusion. Retina. 2007;27(1):49-54. doi:10.1097/ 01.iae.0000221996.77421.69

34. Ma J, Yao K, Zhang Z, Tang X. 25-gauge vitrectomy and triamcinolone acetonide-assisted internal limiting membrane peeling for chronic cystoid macular edema associated with branch retinal vein occlusion. Retina. 2008;28(7):947-956. doi:10.1097/IAE.0b013e31816c683d

35. Kumagai K, Furukawa M, Ogino N, Larson E. Possible effects of internal limiting membrane peeling in vitrectomy for macular vein occlusion. Jpn J Ophthalmol. 2010;54(1):61-65. doi:10.1007/s10384-009-0750-Z

36. Kumagai K, Ogino N, Furukawa M, Larson E. Three treatments for macular edema because of branch retinal vein occlusion: intravitreous bevacizumab or tissue plasminogen activator, and vitrectomy. Retina. 2012;32(3):520-529. doi:10.1097/IAE.0b013e31822529e2

37. Sato T, Sawada K, Iwahashi-Shima C, Bando H, Ikeda T, Emi K. 25 -gauge vitrectomy versus intravitreal bevacizumab for macular edema secondary to branch retinal vein occlusion: 1 year follow-up. Ann Acad Med Singapore. 2012;41(7):294.

38. Yunoki T, Mitarai K, Yanagisawa S, Kato T, Ishida N, Hayashi A. Effects of vitrectomy on recurrent macular edema due to branch retinal vein occlusion after intravitreal injection of bevacizumab. J Ophthalmol. 2013;2013:415974. doi:10.1155/2013/670242

39. Shirakata Y, Fukuda K, Fujita T, et al. Pars plana vitrectomy combined with internal limiting membrane peeling for recurrent macular edema due to branch retinal vein occlusion after antivascular endothelial growth factor treatments. Clin Ophthalmol. 2016;10:277-283. doi:10.2147/OPTH.S85751

40. Thach AB, Yau L, Hoang C, Tuomi L. Time to clinically significant visual acuity gains after ranibizumab treatment for retinal vein occlusion: BRAVO and CRUISE trials. Ophthalmology. 2014;121(5): 1059-1066. doi:10.1016/j.ophtha.2013.11.022

41. Yuan A, Ahmad BU, Xu D, et al. Comparison of intravitreal ranibizumab and bevacizumab for the treatment of macular edema secondary to retinal vein occlusion. Int J Ophthalmol. 2014;7(1):86-91. doi:10.3980/j. issn.2222-3959.2014.01.15

42. Khan M, Wai KM, Silva FQ, et al. Comparison of ranibizumab and bevacizumab for macular edema secondary to retinal vein occlusions in routine clinical practice. Ophthalmic Surg Lasers Imaging Retina. 2017;48(6):465-472. doi:10.3928/23258160-20170601-04

43. Sangroongruangsri S, Ratanapakorn T, Wu O, Anothaisintawee T, Chaikledkaew U. Comparative efficacy of bevacizumab, ranibizumab, and aflibercept for treatment of macular edema secondary to retinal vein occlusion: a systematic review and network meta-analysis. Expert Rev Clin Pharmacol. 2018;11(9):903-916. doi:10.1080/17512433. 2018.1507735

44. Heier JS, Bressler NM, Avery RL, et al. American Society of Retina Specialists Anti-VEGF for Diabetic Macular Edema Comparative Effectiveness Panel. Comparison of aflibercept, bevacizumab, and ranibizumab for treatment of diabetic macular edema: extrapolation of data to clinical practice. JAMA Ophthalmol. 2016;134(1):95-99. doi:10.1001/jamaophthalmol.2015.4110 


\section{Publish your work in this journal}

Clinical Ophthalmology is an international, peer-reviewed journal covering all subspecialties within ophthalmology. Key topics include: Optometry; Visual science; Pharmacology and drug therapy in eye diseases; Basic Sciences; Primary and Secondary eye care; Patient Safety and Quality of Care Improvements. This journal is indexed on

Submit your manuscript here: http://www.dovepress.com/clinical-ophthalmology-journal
PubMed Central and CAS, and is the official journal of The Society of Clinical Ophthalmology (SCO). The manuscript management system is completely online and includes a very quick and fair peer-review system, which is all easy to use. Visit http://www.dovepress.com/ testimonials.php to read real quotes from published authors. 